\title{
Evaluasi Penerapan Program "Peka Perisai" (Studi Kasus Bagian Pemboran dan WOWS PT. Pertamina EP Asset v)
}

\author{
Andri Tri Susanto ${ }^{(1, a) *}$, Maya Dewi Dyah Mahara ${ }^{(1)}$ dan Tatan Sukwika ${ }^{(2)}$ \\ ${ }^{1,2}$ Prodi Magister MK3L, Universitas Sahid Jakarta, Jakarta Pusat, Indonesia, 10220 \\ Email : ${ }^{\left(a^{*}\right)}$ andrie.san@gmail.com
}

Diterima (13 Desember 2021), Direvisi (31 Desember 2021)

\begin{abstract}
Problems in PEP Asset 5 are in the form of unsafe behavior such as lack of knowledge and skills so that they fail to remind, secure, and identify hazards. PEKA PERISAI as an effort to prevent workplace accidents was officially implemented in 2020. This study aims to evaluate the application of PEKA PERISAI, the obstacles in its implementation, and the effect of PEKA PERISAI on K3 in PEP Asset 5. The study uses a qualitative and quantitative approach. Collecting data through interviews, questionnaires, observation, and documentation. Data analysis used ISM (Interpretative Structural Model) to evaluate the objectives and constraints in the application of PEKA PERISAI, and linear regression test to evaluate the effect of PEKA PERISAI on K3 in PEP Asset 5. The driving force is to support the implementation of the Pertamina HSE Golden Rules (Comply, Intervention, and Care), and the second objective is to provide coaching and counseling so that work is carried out safely according to procedures. (2) The evaluation of constraints based on ISM shows that all macro constraints are major obstacles, especially the lack of guidance, guidance, and supervision of hazard control. In 2020, 1,792 unsafe cases were found with 1,517 cases (84.65\%) being human error (3) The application of PEKA PERISAI had a positive and significant effect on OHS by $16 \%$, meaning that by increasing PEKA PERISAI, K3 in PEP Asset 5 can also increase.
\end{abstract}

Keywords: evaluation, hsse, ism, peka perisai, pep.

Abstrak. Permasalahan di PEP Asset 5 berupa perilaku tidak aman seperti kurangnya pengetahuan dan keterampilan sehingga gagal mengingatkan, mengamankan, serta mengidentifikasi bahaya. PEKA PERISAI sebagai upaya pencegahan kecelakaan kerja resmi dilaksanakan tahun 2020. Penelitian ini bertujuan mengevaluasi penerapan PEKA PERISAI, kendala-kendala dalam penerapannya, dan pengaruh PEKA PERISAI terhadap K3 di PEP Asset 5. Penelitian menggunakan pendekatan kualitatif dan kuantitatif. Pengumpulan data melalui wawancara, angket, observasi, dan dokumentasi. Analisis data menggunakan ISM (Interpretative Structural Model) untuk mengevaluasi tujuan dan kendala dalam penerapan PEKA PERISAI, dan uji regresi linear untuk mengevaluasi pengaruh PEKA PERISAI terhadap K3 di PEP Asset 5. Hasil penelitian yaitu (1) Evaluasi tujuan berdasarkan ISM menunjukkan bahwa tujuan utama sebagai penggerak yaitu mendukung penerapan Pertamina HSE Golden Rules (Patuh, Intervensi, dan Peduli), dan didukung tujuan kedua berupa memberikan coaching dan consoling agar pekerjaan aman dilakukan sesuai prosedur. (2) Evaluasi kendala berdasarkan ISM menunjukkan bahwa semua kendala makro menjadi kendala besar terutama kurangnya pembinaan, bimbingan, dan pengawasan pengendalian bahaya. Tahun 2020 ditemukan 1.792 kasus tidak aman dengan 1.517 kasus (84,65 \%) merupakan human error (3) Penerapan PEKA PERISAI berpengaruh positif dan signifikan terhadap K3 sebesar $16 \%$, artinya dengan peningkatkan PEKA PERISAI maka K3 di PEP Asset 5 pun dapat meningkat.

Kata kunci: evaluasi, hsse, ism, peka perisai, pep 


\author{
Susanto: Evaluasi Penerapan Program "Peka Perisai" \\ (Studi Kasus Bagian Pemboran dan WOWS PT.Pertamina EP Asset 5) \\ Jurnal Migasian, e-issn : 2615-6695 / p-issn : 2580-5258
}

\section{PENDAHULUAN}

Kasus kecelakaan yang terjadi di lokasi kerja setiap tahunnya bisa lebih dari 250 juta, sedangkan bahaya di tempat kerja menyebabkan lebih dari 160 juta pekerja sakit, bahkan sebanyak 1,2 juta pekerja kehilangan nyawa yang disebabkan kecelakaan dan sakit di tempat kerja. Akibat hal tersebut, biaya yang dikeluarkan untuk pekerja dan dana sosial justru lebih tinggi dibanding biaya produksi [1]. Kerugian akibat kecelakaan kerja tidak hanya materi, namun juga bisa kehilangan nyawa. Hal tersebut dapat mengganggu keseluruhan proses produksi sehingga jika perusahaan tidak memperhatikan K3 maka kecelakaan dapat tinggi dan kerugian perusahaan semakin meningkat [2].

Manusia memiliki andil dalam kecelakaan kerja lebih sering karena berinteraksi secara langsung dengan alatalat serta mesin untuk produksi. Kecerobohan menjadi hal yang sering dilakukan yang menyebabkan kecelakaan kerja seperti melakukan pekerjaan di bawah beban yang bergantung, berada di lokasi kerja yang kurang aman, mendapatkan penyinaran yang kurang, waktu bekerja pada malam hari, dan peralatan kerja yang tidak digunakan dengan layak digunakan seperti penutup kepala (helm), masker (penutup hidung dan mulut), dan sebagainya [3].

Permasalahan yang ditemukan di pemboran dan WOWS PT.Pertamina EP (PEP) Asset 5 berupa tindakan tidak aman dalam perilaku kerja. Data selama 20142016 menunjukkan bahwa terdapat tindakan tidak aman yang disebabkan faktor personil seperti kurangnya pengetahuan dan keterampilan sehingga gagal untuk mengingatkan dan mengamankan, serta gagal mengikuti prosedur/instruksi dan mengidentifikasi bahaya. Hal ini menjadi dasar penerapan program PEKA PERISAI sebagai upaya dalam pencegahan terhadap kecelakaan kerja yang berpengaruh pada nilai lagging indicator dengan pendekatan HSSE yang dicanangkan sejak akhir tahun 2019 dan resmi dilaksanakan tahun 2020. Penelitian ini bertujuan mengevaluasi penerapan PEKA PERISAI, kendalakendala dalam penerapannya, dan pengaruh penerapan program PEKA PERISAI terhadap K3 di PEP Asset 5.

\section{TINJAUAN PUSTAKA}

Keselamatan kerja sebagai kondisi yang aman dan selamat dari derita dan kerugian di tempat kerja dalam berbagai kondisi seperti saat mengoperasikan alat, bahan, mesin-mesin dalam proses pengolahan, teknik pengepakan, penyimpanan, maupun menjaga dan mengamankan tempat kerja serta lingkungan kerja, sedangkan definisi kesehatan kerja adalah kondisi pekerja yang terhindar dari gangguan fisik dan mental yang disebabkan interaksi dengan pekerjaan dan lingkungannya [4].

Penerapan K3 saat ini berdasarkan standar bertaraf internasional yaitu ISO 45001:2018 yang merupakan pengganti OHSAS 18001:2007. Standar ISO 45001 pertama kali diterbitkan lembaga ISO pada bulan Oktober 2013 dan disusun oleh komite ISO/PC 283 yang memiliki tanggung jawab dalam proses standarisasi. Penyusunan ISO ini diwakili dari 70 negara. Revisi terbaru ISO 45001 telah dipublikasikan pada bulan Maret 2018. Dengan diterbitkannya ISO 45001 maka OHSAS 18001 ditarik secara resmi dengan menunjuk lembaga BSI untuk melakukan prosesnya dengan memberi kesempatan perusahaan-perusahaan melakukan migrasi hingga Maret 2021. ISO 45001 menggunakan panduan struktur sesuai standar sistem manajemen yaitu Annex SL dengan tujuan memudahkan integrasi 
dengan standar sistem manajemen lain seperti ISO 9001 dan ISO 14001.

Tujuan dan manfaat K3 didasarkan pada hukum yang berlaku yaitu UndangUndang tentang Kecelakaan Tahun 1947 No.33, yang dinyatakan berlaku pada tanggal 6 Januari 1951, kemudian disusul dengan Peraturan Pemerintah Tentang Pernyataan berlakunya peraturan Kecelakaan Tahun 1947 (PP No. 2 tahun 1948). Dalam penelitian Elphiana et al. [5], sumber-sumber hukum yang menjadi dasar penerapan program K3 di Indonesia adalah sebagai berikut:

1. Undang-Undang Nomor 1 Tahun 1970 tentang Keselamatan Kerja

2. Undang-Undang Nomor 3 Tahun 1992 tentang Jaminan Sosial Tenaga Kerja

3. Peraturan Pemerintah Nomor 17 Tahun 1993 tentang Penyelenggaraan Program Jaminan Sosial Tenaga Kerja

4. Keputusan Presiden Nomor 22 Tahun 1993 tentang Penyakit yang Timbul karena Hubungan Kerja

5. Peraturan Pendaftaran Kepesertaan, Pembayaran Iuran, Pembayaran Santunan dan Pelayan Jaminan Sosial Tenaga Kerja

6. Undang-Undang Nomor 13 Tahun 2003 tentang Keselamatan dan Kesehatan Kerja

7. Peraturan Pemerintah Nomor 50 Tahun 2012 tentang Penerapan Sistem Manajemen Keselamatan dan Kesehatan Kerja.

Salah satu upaya dalam penerapan K3 adalah dengan pendekatan Behavior Based Safety (BBS). Cooper [6] menjelaskan bahwa BBS adalah suatu proses yang membangun hubungan keamanan yang dilakukan antara manajemen dan pekerja secara berkelanjutan mengenai perilaku terhadap setiap orang dan orang lain, serta usaha untuk berperilaku selamat.
Prinsip dasar penerapan BBS adalah tanpa nama orang yang diamati, tanpa menyalahkan dan secara terbuka/tidak diam-diam (no observee name, no blame, no sneak up). Dalam BBS terjadi proses untuk identifikasi perilaku yang selamat dan/atau yang berisiko dan penerapan tindakan perbaikan yang diperlukan. Hasil dari pelaksanaan observasi BBS akan dilakukan pendataan dan analisa lebih lanjut, untuk mengetahui dan mengatasi kendala-kendala dalam penerapan perilaku selamat dalam bekerja. Proses BBS yang efektif membutuhkan perencanaan yang baik dan pelaksanaan yang konsisten dengan dukungan dan keterlibatan nyata dari para pimpinan sehingga dapat membangun budaya komitmen.

BBS di PEP dilakukan dengan tujuan:

1. Meningkatkan perilaku selamat dan menurunkan risiko di tempat kerja, dengan mengenali dan memberikan apresiasi untuk memperkuat perilaku selamat (safe behavior) dan memberikan umpan balik yang membangun (constructive) terhadap perilaku yang berisiko (at-risk behavior).

2. Peningkatan saling kepedulian terhadap sesama akan keselamatan dengan pendekatan interaksi dan komunikasi untuk terciptanya saling percaya (trust).

3. Meningkatkan safety behavior dikalangan pekerja dengan mengenali dan mengatasi kendala-kendala terhadap perilaku yang selamat, berdasarkan hasil analisa pengamatan perilaku.

4. Mendukung penerapan HSE Golden Rules (patuh, intervensi, peduli).

\section{METODE PENELITIAN}

Penelitian ini dilaksanakan di bagian pemboran dan WOWS PEP Asset 5. Waktu penelitian dilakukan pada tahun 2021. Sumber data dalam penelitian yaitu sumber primer yang diperoleh langsung dari informan melalui wawancara, angket, dan 
Susanto: Evaluasi Penerapan Program "Peka Perisai"

(Studi Kasus Bagian Pemboran dan WOWS PT.Pertamina EP Asset 5)

Jurnal Migasian, e-issn : 2615-6695 / p-issn : 2580-5258

observasi. Wawancara dilakukan kepada HSE Coach dan bagian manajemen, sedangkan kuesioner diberikan kepada pekerja untuk mengetahui pengaruh penerapan PEKA PERISAI terhadap K3. Observasi dilakukan dalam penelitian ini dilakukan dengan mengamati berbagai hal yang berkaitan dengan perilaku aman pekerja di PEP Asset 5. Sumber lain yaitu sumber sekunder berupa dokumentasi yang meliputi buku-buku dan jurnal-jurnal yang mendukung penelitian, peraturan-peraturan yang berkaitan dengan K3, kebijakan BBS di pemboran dan WOWS PEP Asset 5, dan data-data dari lokasi penelitian yang berkaitan dengan BBS.

Teknik pengambilan sampel untuk metode wawancara dilakukan dengan metode snowball, sedangkan pengambilan sampel untuk angket menggunakan menggunakan purposive sampling, yaitu populasi sudah ditentukan sesuai dengan tujuan penelitian. Populasi dalam penelitian ini yaitu seluruh pekerja lapangan di PEP Asset 5 yang terlibat program PEKA PERISAI.

Metode analisis data dalam penelitian ini menggunakan Interpretative Structural Modelling (ISM) yang dikembangkan oleh Saxena [7] dan analisis regresi linear. ISM untuk mengevaluasi penerapan PEKA PERISAI berdasarkan tujuan dan kendala, sedangkan analisis regresi linear untuk mengukur pengaruh PEKA PERISAI terhadap K3 di PEP Asset 5.

\section{HASIL DAN PEMBAHASAN}

\section{A. Gambaran Umum PEP Asset 5}

Bagian pemboran di PEP merupakan kegiatan eksplorasi dan eksploitasi minyak dan gas. PEP Asset 5 beroperasi di bawah pengawasan PEP dan menyediakan kebutuhan energi nasional dari wilayah Kalimantan. PEP Asset 5 mengoperasikan field Sanga-Sanga dan Sangatta
(Kalimantan Timur), dan Bunyu (Kalimantan Utara). Terdapat 16 rig di lokasi Sanga-Sanga, 2 rig di Sangatta, dan 7 rig di Bunyu.

Dua lokasi penting di PEP Asset 5 yaitu pemboran dan well service dan work service (WOWS). Irawan \& Wibawa [8] mengemukakan bahwa pemboran sumur merupakan langkah lanjutan dari pencarian untuk membuktikan ada atau tidaknya sumber cadangan minyak dan gas dengan membuat lubang secara bertahap hingga kedalaman yang disesuaikan dengan hasil studi dan evaluasi kondisi bawah tanah dari data seismik. Menurut Khan et al., [9], kegiatan operasional dalam pemboran merupakan kegiatan yang dianggap paling berbahaya karena resiko tinggi dalam proses eksplorasi dan eksploitasi minyak dan gas bumi. Hal tersebut juga didukung oleh pendapat Rubiandini [10] bahwa pemboran sumur migas merupakan proyek dengan risiko tinggi (high risk) serta memerlukan biaya tinggi (high cost), bahkan sebuah sumur sering gagal dilanjutkan karena bersifat tinggi risiko dan hasilnya tidak dapat diperkirakan (unpredictable) sehingga biaya yang dikeluarkan secara ekonomis sudah tidak layak dilanjutkan.

Bagian yang perlu diperhatikan setelah pemboran adalah well service dan work service (WOWS). Well service atau perawatan sumur yang rutin untuk mempertahankan produksi atau memperbaiki sumur tanpa mengubah zona produksi, sedangkan work over atau kerja ulang merupakan pekerjaan untuk memperbaiki atau menambah produksi tetapi dengan cara-cara mengubah atau mengolah zona produksi atau mengganti zona produksi. Bagian WOWS perlu dilakukan karena penyebab kehilangan produksi dan penyebab kerusakan. 


\section{B. Penerapan PEKA PERISAI di PEP Asset 5}

Pelaksanaan PEKA PERISAI dengan menggunakan pendekatan behavioral safety (perilaku pekerja) dengan Standar Operational Procedure (SOP) berikut:

1. Observer memberikan informasi mengenai tujuan observasi dalam PEKA PERISAI

2. Observer melakukan pengamatan sesuai lembar panduan berisi indikatorindikator pengamatan untuk menilai perilaku kerja yang dikategorikan Safe, NC (Non Conformance), HE (Human Error), AR (At Risk), dan R (Reckless)

3. Observer dapat melakukan intervensi jika ditemukan perilaku tidak aman dengan tenang tanpa judgment atau menyalahkan pekerja,

4. Observer dan pekerja melakukan dialog yang merupakan inti PEKA PERISAI yang berisi pengalaman kerja, kesulitan yang dihadapi, dan yang dihadapi pekerja, dan observer menerima berbagai cerita maupun tanggapan pekerja tanpa menyudutkan atau menghakimi pekerja jika melakukan kesalahan yang akhirnya terjadi diskusi,

5. Menyimpulkan hasil dialog serta membuat kesepakatan antara observer dan pekerja untuk menerapkan perilaku aman, dan

6. Observer membuat laporan hasil observasi dalam PEKA Online.

Untuk dapat mengidentifikasi perilaku aman atau tidak aman dalam bekerja, maka menggunakan indikator PEKA PERISAI terdiri dari 19 indikator yang digunakan untuk pengamatan yaitu tools \& equipment, safe zone position, STK \& permit to work, isolation, confined space, lifting operation, fit to work, working at height, drop object, excavation, gas test, driving, alat pelindung diri, pelindung tersandung dan terjatuh, bahan kimia, pekerjaan panas, penggunaan bahan peledak, electric safety, dan penggunaan radioaktif.

\section{Evaluasi Penerapan PEKA PERISAI di PEP Asset 5 dengan ISM}

Interpretative Structural Modeling (ISM) menghasilkan 3 hal yaitu elemen kunci, struktur hirarki elemen, dan pengelompokan elemen dalam empat sektor klasifikasi (independent, linkage, dependent, dan autonomous). Sektor independent merupakan elemen yang memiliki kekuatan penggerak besar namun memiliki tingkat ketergantungan yang kecil. Sektor linkage merupakan sektor yang memiliki hubungan antar peubah yang tidak stabil dan setiap perubahan tindakan dari peubah tersebut akan berdampak terhadap sub-elemen lainnya sehingga sub-elemen sektor linkage harus dikaji dengan hati-hati. Sektor dependent merupakan sub-elemen yang tidak bebas. Sektor autonomus merupakan sub-elemen yang tidak terkait langsung dengan sistem, memiliki hubungan yang kecil, namun memiliki pengaruh kuat dalam pencapaian tujuan [11].

Untuk mengevaluasi program PEKA PERISAI di. PEP Asset 5 menggunakan ISM, dua hal yang menjadi fokus penelitian yaitu tujuan dan kendala.

\section{Evaluasi Tujuan PEKA PERISAI Berdasarkan ISM}

Berdasarkan wawancara mendalam dan diskusi dengan para pakar di PEP Asset 5 yaitu HSE coach, terdapat 10 tujuan yang ingin dicapai dalam PEKA PERISAI meliputi:

a. Mendukung Pertamina HSE Golden Rules: Patuh, Intervensi, dan Peduli (E1).

b. Memastikan pekerjaan berisiko tinggi di kegiatan pemboran, WO-WS, dan project dilaksanakan dengan aman (E2). 
c. Membentuk safety culture yang baik di level frontliner PEP (E3).

d. Mencegah terjadinya kecelakaan kerja di kegiatan operasi PEP (E4).

e. Melatih kepekaan dan keberanian pekerja untuk menghentikan aktivitas/pekerjaan yang dinilai membahayakan sekali (E5).

f. Memberikan motivasi kepada pekerja mempertahankan perilaku selamat (E6).

g. Membangun budaya komunikasi HSSE antar pekerja sebagai perbaikan langsung dan pembelajaran atas hasil observasi yang dilakukan (E7).

h. Menjadi wadah/media pelaporan atas observasi yang dilakukan dan menjadi sumber informasi yang akan digunakan untuk melihat kecenderungan dari perilaku berisiko dan kondisi berbahaya yang terjadi sehingga dapat ditentukan tindakan pencegahan dan perbaikan agar tidak terulang (E8).

i. Melakukan observasi untuk menentukan tindakan pencegahan dan perbaikan agar tidak terulang (E9).

j. Memberikan coaching dan consoling sebagai pelatihan atas perilaku kerja yang tidak aman sehingga pekerja mendapatkan pengetahuan kerja aman sesuai dengan prosedur (E10).

Hubungan antar elemen tujuan PEKA PERISAI diperoleh dari pendapat akademisi. Structural Self-Interaction Matrix (SSIM) awal kemudian disusun berdasarkan hubungan antar elemen tujuan. Interpretasi Reachability Matrix elemen tujuan disajikan berikut:
Tabel 1. Reachability Matrix final dan interpretasi elemen tujuan

\begin{tabular}{llllllllllll}
\hline No & E1 & E2 & E3 & E4 & E5 & E6 & E7 & E8 & E9 & E10 & Drv \\
\hline E1 & 1 & 1 & 1 & 1 & 1 & 1 & 1 & 1 & 1 & 1 & 10 \\
\hline E2 & 0 & 1 & 1 & 1 & 1 & 1 & 1 & 1 & 1 & 0 & 8 \\
\hline E3 & 0 & 1 & 1 & 1 & 1 & 1 & 1 & 1 & 1 & 0 & 8 \\
\hline E4 & 0 & 1 & 1 & 1 & 1 & 1 & 1 & 1 & 1 & 0 & 8 \\
\hline E5 & 0 & 1 & 1 & 1 & 1 & 1 & 1 & 1 & 1 & 0 & 8 \\
\hline E6 & 0 & 1 & 1 & 1 & 1 & 1 & 1 & 1 & 1 & 0 & 8 \\
\hline E7 & 0 & 1 & 1 & 1 & 1 & 1 & 1 & 1 & 1 & 0 & 8 \\
\hline E8 & 0 & 0 & 0 & 0 & 0 & 0 & 0 & 1 & 0 & 0 & 1 \\
\hline E9 & 0 & 1 & 1 & 1 & 1 & 1 & 1 & 1 & 1 & 0 & 8 \\
\hline E10 & 0 & 1 & 1 & 1 & 1 & 1 & 1 & 1 & 1 & 1 & 9 \\
\hline Dep & 1 & 9 & 9 & 9 & 9 & 9 & 9 & 10 & 9 & 2 & \\
\hline
\end{tabular}

Berdasarkan Tabel 1 di atas dapat dilihat bahwa Driver Power tertinggi atau elemen kunci yang merupakan tujuan paling utama dan prioritas untuk dicapai di PEP adalah mendukung penerapan Pertamina HSE Golden Rules, yakni Patuh, Intervensi, dan Peduli. Tujuan tersebut menjadi pendorong terbesar dalam penerapan PEKA PERISAI di PEP Asset 5 dalam menekan kecelakaan kerja. Sub elemen tujuan yang mempunyai prioritas terpenting kedua adalah memberikan coaching dan consoling sebagai pelatihan atas perilaku kerja yang tidak aman sehingga pekerja mendapatkan pengetahuan kerja aman sesuai dengan prosedur. Artinya, dengan coaching dan consoling sebagai pelatihan atas perilaku kerja memberikan peran besar dalam tercapainya HSE Golden Rules.

Berdasarkan Driver Power $(D P)$ dan Dependence, ke-10 sub elemen dikelompokkan ke dalam 4 sektor (Gambar 1).

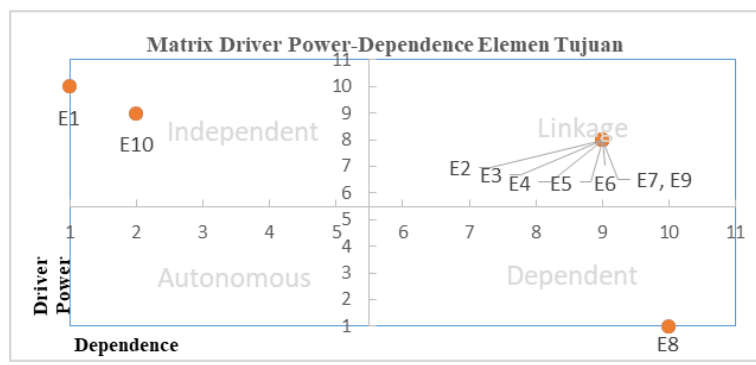

Gambar 1. Matrix Driver Power-Dependence Elemen Tujuan 
Dikemukakan oleh Maharani \& Sara [11] bahwa analisis klasifikasi dari setiap elemen menunjukkan adanya peubah tidak bebas dan terpengaruh oleh program yang dijalankan, yaitu sebagai tindakan tujuan dari sub-sub elemen lainnya. Dari Gambar 1 terlihat bahwa sub elemen tujuan mendukung penerapan Pertamina HSE Golden Rules, yakni Patuh, Intervensi, dan Peduli (E1) berada pada sektor independent (IV) dan memiliki daya dorong paling besar untuk mencapai tujuan lainnya dalam penerapan PEKA PERISAI. Peringkat daya dorong kedua adalah tujuan memberikan coaching dan consoling sebagai pelatihan atas perilaku kerja yang tidak aman sehingga pekerja mendapatkan pengetahuan kerja aman sesuai dengan prosedur. Hal ini menunjukkan bahwa HSE Golden Rules serta pemberian coaching dan consoling mendorong tujuan lainnya untuk dapat tercapai dengan baik (E10). Dengan daya gerak yang besar dan ketergantungan terhadap sistem yang rendah, pencapaian kedua tujuan tersebut dapat mendorong pencapaian tujuan lainnya dalam penerapan PEKA PERISAI.

Elemen tujuan yang masuk ke dalam sektor linkage (III) adalah memastikan bahwa pekerjaan berisiko tinggi di kegiatan pemboran, WO-WS dan project dilaksanakan dengan aman (E2), membentuk safety culture yang baik di level frontliner PEP (E3), mencegah terjadinya kecelakaan kerja di kegiatan operasi PEP (E4), melatih kepekaan dan keberanian pekerja untuk menghentikan aktivitas atau pekerjaan yang dinilai membahayakan sekali (E5), memberikan motivasi kepada pekerja untuk mempertahankan perilaku selamat (E6), membangun budaya komunikasi HSSE antar pekerja sebagai perbaikan langsung dan pembelajaran atas hasil observasi yang dilakukan (E7), dan melakukan observasi untuk menentukan tindakan pencegahan dan perbaikan agar tidak terulang (E9).
Dengan berada di sektor ini, ketujuh elemen tujuan tersebut sangat tergantung pada sistem, namun juga memberikan dampak besar bagi tercapainya tujuan lainnya. Dengan pencapaian ketujuh tujuan ini maka tujuan lainnya dapt tercapai dengan baik.

Elemen tujuan E8 yaitu menjadi wadah/media pelaporan observasi yang dilakukan dan menjadi sumber informasi yang akan digunakan untuk melihat kecenderungan perilaku berisiko dan kondisi berbahaya yang terjadi sehingga dapat ditentukan tindakan pencegahan dan perbaikan agar tidak terulang. Sektor ini dikategorikan weak driver-strongly dependent variable (II), artinya sangat tergantung dengan sistem dan tujuan lainnya.

Penerapan Pertamina HSE Golden Rules, yakni Patuh, Intervensi, dan Peduli menjadi prioritas utama dalam program PEKA PERISAI mengingat berbagai potensi pekerjaan di pemboran dan WOWS yang dapat menyebabkan kecelakaan kerja. Patuh artinya setiap unsur dalam perusahaan wajib patuh pada kebijakan dan peraturan terkait HSSE, intervensi yaitu siapapun yang bekerja di dalamnya dapat mengintervensi apabila ditemukan kondisi yang tidak aman, serta peduli diwujudkan dengan saling memperhatikan dan memperdulikan satu sama lain di setiap wilayah kerja. Dengan penerapan Golden Rules diharapkan dapat menekan angka kecelakaan kerja.

\section{Evaluasi Kendala PEKA PERISAI berdasarkan ISM}

Berdasarkan hasil wawancara mendalam dan diskusi dengan para pakar di PEP Asset 5 yaitu HSE coach dan manajemen HSE, kendala meliputi kendala makro dan kendala mikro. Berikut ini berbagai permasalahan yang telah disusun berdasarkan wawancara dengan para ahli: 
Susanto: Evaluasi Penerapan Program "Peka Perisai"

(Studi Kasus Bagian Pemboran dan WOWS PT.Pertamina EP Asset 5)

Jurnal Migasian, e-issn : 2615-6695 / p-issn : 2580-5258

a. Kurangnya pembinaan, bimbingan, pengawasan, serta bidang pengendalian bahaya (E1).

b. Adanya peraturan tenaga kerja AKAD dan AKAL yang menyebabkan pergantian tenaga kerja tinggi (E2).

c. Fasilitas untuk pelatihan dan sertifikasi industri migas masih terbatas, yaitu berada di kota Cepu, Jakarta, dan Palembang (E3).

d. Perkembangan tekonologi perlu diantisipasi agar bahaya yang ditimbulkan dapat diminimalisir atau dihilangkan (E4)

e. Adanya kesenjangan sosial budaya dalam bentuk rendahnya disiplin dan kesadaran masyarakat terhadap masalah keselamatan kerja (E5)

f. Culture masing-masing daerah yang berbeda sehingga menyebabkan komunikasi tentang keselamatan kerja kurang berjalan maksimal (E6)

g. Kesadaran, dukungan, dan keterlibatan manajemen operasi terhadap usaha pengendalian bahaya dirasakan masih kurang (E7)

h. Anggapan keselamatan dan kesehatan kerja (K3) adalah cost center (E8)

i. Kemampuan petugas keselamatan kerja di bidang rekayasa operasi dan keselamatan kerja, dan manajemen pengendalian bahaya masih kurang (E9)

j. Wewenang petugas keselamatan kerja yang terbatas saat menyampaikan keadaan atau kondisi tidak aman yang dapat menyebabkan insiden (E10)

k. Kurangnya acuan dan standar keselamatan kerja industri migas yang menggunakan bahasa Indonesia (E11)

Hubungan antar elemen kendala dalam penerapan PEKA PERISAI diperoleh dari pendapat akademisi. Interpretasi dari Reachability Matrix elemen kendala disajikan berikut:
Tabel 2. Reachability Matrix final dan interpretasi elemen kendala

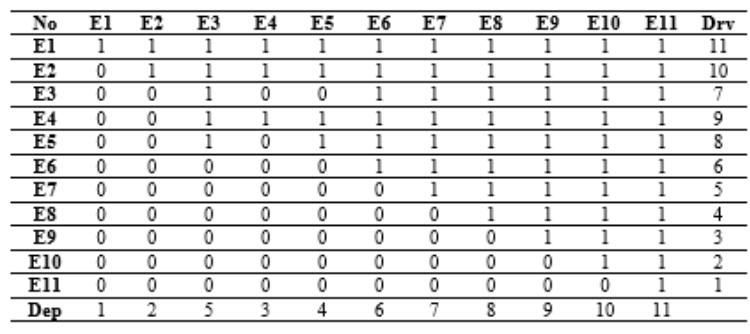

Berdasarkan Tabel di atas, Driver Power tertinggi atau elemen kunci yang merupakan kendala paling besar dalam penerapan PEKA PERISAI di PEP adalah masih dirasa adanya kekurangan dalam masalah pembinaan, bimbingan, pengawasan, serta bidang-bidang pengendalian bahaya. Sub elemen kendala yang kedua adalah adanya peraturan tentang tenaga kerja AKAD dan AKAL yang menyebabkan pergantian tenaga kerja menjadi tinggi.

Berdasarkan Driver Power (DP) dan Dependence, ke-11 sub elemen dikelompokkan ke dalam 4 sektor (Gambar 2.).

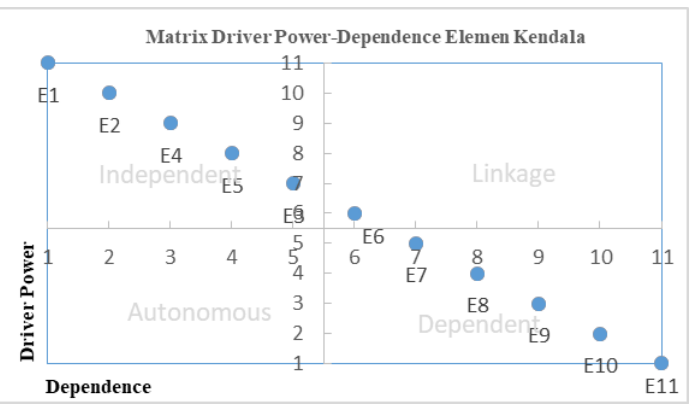

Gambar 2. Matrix Driver Power-Dependence Elemen Kendala

Berdasarkan Gambar 2 di atas terlihat bahwa sub elemen kendala dalam penerapan PEKA PERISAI paling besar adalah E1, yaitu masih dirasa adanya kekurangan dalam masalah pembinaan, bimbingan, pengawasan, serta bidangbidang pengendalian bahaya. Kendala ini 
berada pada sektor independent (IV) bersama dengan kendala lainnya yaitu adanya peraturan tentang tenaga kerja AKAD dan AKAL yang menyebabkan pergantian tenaga kerja menjadi tinggi (E2), perkembangan tekonologi yang perlu diantisipasi agar bahaya yang ditimbulkan dapat diminimalisir atau dihilangkan (E4), adanya kesenjangan sosial budaya dalam bentuk rendahnya disiplin dan kesadaran masyarakat terhadap masalah keselamatan kerja (E5), dan fasilitas untuk pelatihan dan sertifikasi industri migas masih terbatas, yaitu berada di kota Cepu, Jakarta, dan Palembang (E3). Kelima kendala ini berada pada sektor independent (IV) dan memiliki pengaruh paling besar yang menentukan pencapaian tujuan PEKA PERISAI. Dengan daya gerak yang besar dan ketergantungan terhadap sistem yang rendah, kelima kendala tersebut dapat menjadi penghambat dalam penerapan PEKA PERISAI.

Elemen kendala yang masuk dalam sektor linkage (III) adalah E6, yaitu culture masing-masing daerah yang berbeda sehingga menyebabkan komunikasi tentang keselamatan kerja kurang berjalan maksimal. Kendala di sektor ini sangat tergantung pada sistem, namun juga berdampak terhadap kendala lainnya. Kendala mengenai culture masing-masing daerah tersebut berpengaruh pada kendala lain dalam penerapan PEKA PERISAI.

Lima kendala berada pada sektor dependent (II) yaitu kesadaran, dukungan, dan keterlibatan manajemen operasi terhadap usaha pengendalian bahaya dirasakan masih kurang (E7), anggapan bahwa keselamatan dan kesehatan kerja (K3) adalah cost center (E8), kemampuan petugas keselamatan kerja di bidang rekayasa operasi, rekayasa keselamatan kerja, dan manajemen pengendalian bahaya dirasakan masih kurang (E9), wewenang petugas keselamatan kerja yang terbatas saat menyampaikan keadaan atau kondisi tidak aman yang dapat menyebabkan insiden (E10), dan kurangnya acuan dan standar keselamatan kerja industri migas yang menggunakan bahasa Indonesia (E11). Sektor ini dikategorikan weak driverstrongly dependent variable (II), artinya sangat tergantung dengan sistem dan kendala lainnya.

Berdasarkan evaluasi menggunakan ISM di atas, maka gambaran model struktural program PEKA PERISAI di PEP Asset 5 disajikan pada gambar berikut ini:

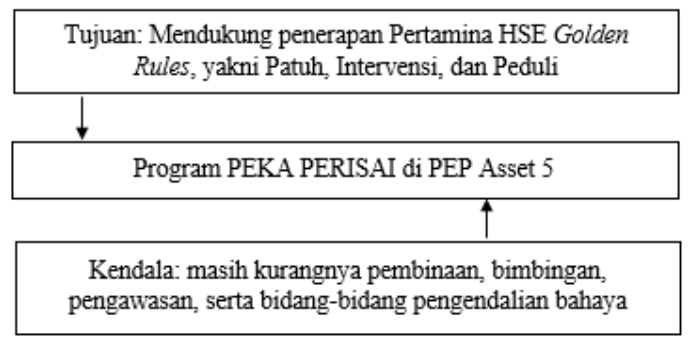

Gambar 3. Model Struktural Program PEKA PERISAI di PEP Asset 5

\section{Pengaruh penerapan PEKA PERISAI terhadap K3 di PEP Aset 5}

Untuk mengetahui pengaruh penerapan program PEKA PERISAI terhadap keselamatan dan kesehatan kerja (K3) di PEP Asset 5 dilakukan dengan uji regresi linear terhadap angket yang telah disebarkan kepada 135 responden yang merupakan pekerja di lokasi kerja tersebut.

\section{Karakteristik responden}

Keseluruhan responden dalam penelitian ini adalah laki-laki mengingat lokasi kerja yaitu pemboran dan WOWS migas dengan risiko tinggi dan membutuhkan fisik serta mental kuat yang umumnya dimiliki laki-laki. Berdasarkan karakteristik usia, responden dalam penelitian ini berdasarkan umur berada pada rentang 27 - 55 Responden paling banyak berusia 45 tahun yaitu sebanyak 14 responden $(10,4 \%)$, sedangkan responden paling sedikit berusia 27 tahun, 28 tahun, dan 41 tahun yang 
Susanto: Evaluasi Penerapan Program "Peka Perisai"

(Studi Kasus Bagian Pemboran dan WOWS PT.Pertamina EP Asset 5)

Jurnal Migasian, e-issn : 2615-6695 / p-issn : 2580-5258

masing-masing sebanyak 1 responden $(0,7 \%)$. Jumlah terbanyak kedua berusia 43 tahun dan 47 tahun masing-masing berjumlah 13 responden $(9,6 \%)$. Adapun terbanyak berikutnya yaitu usia 35 tahun sebanyak 11 orang $(8,1 \%)$, usia 42 tahun sebanyak 10 orang $(7,4$ $\%$ ), dan usia 44 tahun sebanyak 9 orang $(6,7 \%)$. Dapat disimpulkan bahwa responden didominasi usia $\geq 42$ tahun.

Berdasarkan karakteristik lama bekerja, lama bekerja responden paling banyak yaitu 5 tahun sebanyak 21 orang $(15,6 \%)$, berikutnya lama bekerja 3 tahun yaitu 18 responden $(13,3 \%)$ dan 6 tahun sebanyak 16 orang $(11,9 \%)$. lama bekerja didominasi oleh pekerja dengan lama bekerja $\leq 6$ tahun dengan jumlah 80 responden atau separuh lebih. Hal ini disebabkan peraturan yang memberlakukan pemberdayaan masyarakat sekitar dalam rangka penyerapan tenaga kerja, sedangkan dalam aktivitas pemboran memungkinkan sering pindah. Hal tersebut menjadi alasan seringnya pergantian tenaga kerja.

Berdasarkan posisi pekerjaan, paling banyak yaitu floorman (24 orang atau $17,8 \%$ ), dan terbanyak berikutnya adalah derrickman yaitu 12 orang $(8,9 \%)$. Floorman (operator lantai bor) merupakan pekerja yang membantu driller di bekerja di rig floor pada saat melakukan pekerjaan koneksi ataupun unkoneksi pada pipa-pipa pengeboran. Derrickman merupakan operator menara bor, bertugas di ketinggian membantu driller menyusun pipa-pipa bor pada jari-jari Monkey Board yang berada di atas menara rig. Jumlah paling sedikit yaitu ADM, operator dan paritan masing-masing 1 orang responden $(0,7 \%)$.

\section{Pengaruh Penerapan PEKA PERISAI terhadap K3 di PEP Asset 5}

Pengaruh penerapan PEKA PERISAI terhadap K3 dilakukan dengan uji regresi linear, dengan variabel penerapan PEKA PERISAI sebagai variabel bebas (X) dan K3 di PEP sebagai variabel terikat (Y). Sebanyak 20 item pernyataan variabel bebas dan 20 pernyataan variabel terikat telah diuji validitas dan reliabilitas dengan menggunakan program SPSS yang menunjukkan item valid dan reliabel sehingga digunakan dalam uji regresi.

Uji regresi linear bertujuan untuk mengetahui pengaruh variabel bebas yaitu penerapan PEKA PERISAI terhadap variabel terikat (K3). Hasil perhitungan dengan menggunakan SPSS dapat dilihat pada tabel berikut:

Tabel 3. 16 Output regresi linear

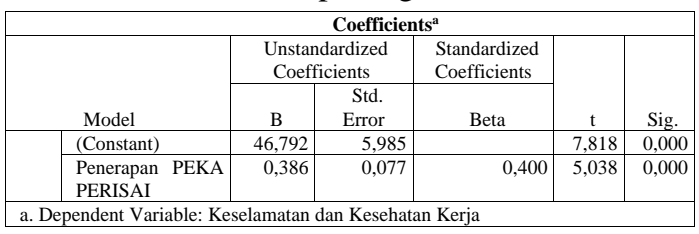

Sumber: Lampiran diolah

Berdasarkan tabel di atas dapat dilihat bahwa variabel bebas $(\mathrm{X})$ yaitu penerapan PEKA PERISAI memiliki signifikansi sebesar 0,000 . Nilai signifikansi ini $<0,05$, sehingga dapat disimpulkan bahwa penerapan PEKA PERISAI (X) berpengaruh terhadap variabel terikat $(\mathrm{Y})$ yaitu Keselamatan dan Kesehatan Kerja (K3) di PT. Pertamina EP Asset 5.

Hasil output SPSS menunjukkan bahwa penerapan PEKA PERISAI memiliki signifikansi sebesar 0,000 (< 0,05), sehingga dapat disimpulkan bahwa penerapan PEKA PERISAI (X) 
berpengaruh terhadap variabel terikat (Y) yaitu Keselamatan dan Kesehatan Kerja (K3) di PEP Asset 5. Persamaan regresi yang tersusun disajikan sebagai berikut:

$$
\mathrm{Y}=46,792+0,386 \mathrm{X}
$$

Dari persamaan di atas dapat disimpulkan pengaruh antara variabel bebas yaitu penerapan PEKA PERISAI (X) terhadap Keselamatan dan Kesehatan Kerja (K3) (Y), yaitu:

a. Konstanta sebesar 46,792; artinya jika penerapan PEKA PERISAI (X) nilainya konstan, maka Keselamatan dan Kesehatan Kerja (K3) (Y) nilainya sebesar 46,792.

b. Koefisien regresi variabel penerapan PEKA PERISAI (X) sebesar 0,386; artinya jika variabel bebas lainnya nilainya tetap dan variabel penerapan PEKA PERISAI (X) mengalami kenaikan 1\%, maka $\mathrm{K} 3$ (Y) akan mengalami kenaikan sebesar 0,386. Koefisien bernilai positif artinya terjadi hubungan positif antara penerapan PEKA PERISAI dengan Keselamatan dan Kesehatan Kerja (K3), semakin naik angka penerapan PEKA PERISAI maka semakin meningkat Keselamatan dan Kesehatan Kerja (K3) di PEP Asset 5.

Dari hasil perhitungan diperoleh $\mathrm{R}^{2}$ sebesar 0,160 atau $16 \%$. Hal ini menunjukkan bahwa pengaruh penerapan PEKA PERISAI (X) sebesar $16 \%$ terhadap Keselamatan dan Kesehatan Kerja (K3) di PEP Asset 5 (Y) dan sisanya yaitu $84 \%$ dipengaruhi oleh variabel lain yang tidak diteliti.

\section{KESIMPULAN}

Permasalahan yang ditemukan di pemboran dan WOWS PT.Pertamina EP (PEP) Asset 5 berupa tindakan tidak aman dalam perilaku kerja. Data selama
2014-2016 menunjukkan bahwa terdapat tindakan tidak aman yang disebabkan faktor personil seperti kurangnya pengetahuan dan keterampilan sehingga gagal untuk mengingatkan dan mengamankan, serta gagal mengikuti prosedur/instruksi dan mengidentifikasi bahaya. Hal ini menjadi dasar penerapan program PEKA PERISAI sebagai upaya dalam pencegahan terhadap kecelakaan kerja dengan pendekatan HSSE yang dicanangkan sejak akhir tahun 2019 dan resmi dilaksanakan tahun 2020. Penelitian ini bertujuan mengevaluasi penerapan PEKA PERISAI, kendalakendala dalam penerapannya, dan pengaruh penerapan program PEKA PERISAI terhadap K3 di PEP Asset 5. Berikut ini kesimpulan yang menjawab tujuan berdasarkan hasil evaluasi dalam penelitian ini:

1. Penerapan PEKA PERISAI yang telah dilaksanakan pada tahun 2020 di PEP Asset 5 memiliki 10 tujuan sebagai goal penerapan PEKA PERISAI. Hasil evaluasi tujuan penerapan PEKA PERISAI di PEP Asset 5 menggunakan Interpretative Structural Model (ISM) menunjukkan bahwa dari 10 tujuan PEKA PERISAI terdapat tujuan utama sebagai kekuatan penggerak besar namun memiliki tingkat ketergantungan yang kecil yaitu mendukung penerapan Pertamina HSE Golden Rules (Patuh, Intervensi, dan Peduli). Sebagai upaya pendekatan K3 berdasarkan behavioral safety, PEKA PERISAI juga memfokuskan pada tindakan memberikan coaching dan consoling sebagai pelatihan atas perilaku kerja yang tidak aman sehingga pekerja mendapatkan pengetahuan kerja aman sesuai dengan prosedur. Coaching dan consoling merupakan elemen kunci kedua dari tujuan 


\begin{abstract}
Susanto: Evaluasi Penerapan Program "Peka Perisai"
(Studi Kasus Bagian Pemboran dan WOWS PT.Pertamina EP Asset 5)

Jurnal Migasian, e-issn : 2615-6695 / p-issn : 2580-5258
\end{abstract}

PEKA PERISAI dengan kekuatan penggerak besar.

2. Secara rinci kendala yang dihadapi dalam penerapan PEKA PERISAI di PT.Pertamina EP Asset 5 dibagi menjadi 2 yaitu kendala makro dan mikro. Evaluasi berdasarkan ISM menunjukkan bahwa beberapa kendala makro menjadi kendala yang kuat dengan ketergantungan kecil (sektor independent) meliputi:

a. Adanya peraturan tentang tenaga kerja AKAD dan AKAL yang menyebabkan pergantian tenaga kerja menjadi tinggi,

b. Perkembangan teknologi perlu diseimbangkan dengan kompetensi pekerja agar bahaya yang ditimbulkan dapat diminimalisir atau dihilangkan

c. Masih kurangnya pembinaan, bimbingan, pengawasan, serta bidang-bidang pengendalian bahaya. Kendala-kendala tersebut menyebabkan tujuan PEKA PERISAI belum tercapai dengan maksimal yang juga ditunjukkan dari hasil observasi sepanjang tahun 2020 di mana masih ditemukan 1.792 kasus tidak aman (Non Conformance) dengan 1.517 kasus $(84,65 \%)$ merupakan human error di bagian tools \& equipment, safe zone position, STK \& Permit to Work, lifting operation, dan alat pelindung diri.

3. Penerapan PEKA PERISAI di PT.Pertamina EP Asset 5 memberikan pengaruh positif dan signifikan dengan terhadap K3 nilai signifikansi sebesar $0,000(<0,05)$ dan persamaan regresi linear $\mathrm{Y}=$ $46,792+0,386 X$ yang menunjukkan bahwa jika penerapan PEKA PERISAI (X) nilainya konstan, maka K3 (Y) nilainya sebesar konstanta yaitu 46,792, sedangkan jika penerapan PEKA PERISAI (X) mengalami kenaikan 1\%, K3 (Y) akan mengalami kenaikan sebesar 0,386. Koefisien bernilai positif artinya terjadi hubungan positif antara penerapan PEKA PERISAI dengan K3, artinya semakin naik angka penerapan PEKA PERISAI maka semakin meningkat $\mathrm{K} 3$ di PT.Pertamina EP Asset 5. Besarnya pengaruh penerapan PEKA PERISAI terhadap K3 sebesar $16 \%$. Hal ini menunjukkan bahwa PEKA PERISAI perlu ditingkatkan untuk menunjang K3 sehingga dapat menurunkan angka insiden di PT. Pertamina EP Asset 5.

\section{UCAPAN TERIMAKASIH}

Penelitian ini dapat dilaksanakan dengan baik berkat bantuan dari berbagai pihak. Untuk itu peneliti ucapkan terima kasih kepada para HSE Coach, kepala manajemen, serta para pegawai/karyawan PT.Pertamina EP Asset 5 yang terlibat dalam penelitian ini.

\section{DAFTAR PUSTAKA}

[1] N. Haworth and S. Hughes, The International Labour Organization. 2012.

[2] N. Fridayanti and R. Kusumasmoro, "Penerapan Keselamatan Dan Kesehatan Kerja Di PT Ferron Par Pharmaceuticals Bekasi," J. Adm. Kant., vol. 4, no. 1, pp. 211-234, 2016.

[3] E. A. Marom and B. S. Sunuharyo, "Pengaruh Keselamatan dan Kesehatan Kerja (K3) Terhadap Kinerja Karyawan (Studi pada Karyawan bagian Produksi Perusahaan PT Lion Metal Works 
Tbk)," J. Adm. Bisnis, vol. 60, no. 1, pp. 187-194, 2018.

[4] W. S. Kuswana, Ergonomi dan K3 (Kesehatan dan Keselamatan Kerja). Bandung: PT. Remaja Rosdakarya, 2014.

[5] \& M. K. Z. Elphiana E.G, Yuliansyah M. Diah, "Pengaruh Keselamatan Dan Kesehatan Kerja Terhadap Kinerja Karyawan Pt. Pertamina Ep Asset 2 Prabumulih," JEMBATANB- J. Ilm. Manaj. Bisnis Dan Terap., no. 2, pp. 103-118, 2017.

[6] M. D. Cooper, Behavioral Safety a Framework for Success. Indiana: BSMS Inc, 2009.

[7] Eriyatno, Ilmu Sistem Meningkatkan Mutu dan Efektivitas Manajemen. Bogor: IPB Press, 1999.

[8] G. Irawan and B. M. Wibawa, "Analisis Peta Risiko Pengeboran di
Wilayah Asset 5 PT Pertamina EP," J. Manaj. dan Kewirausahaan, vol. 17, no. 2, pp. 113-125, 2015.

[9] F. I. Khan, R. Sadiq, and T. Husain, "Risk based process safety assesment and control measures design for offshore process facilities," $J$. Hazard. Mater., vol. 94, no. 1, pp. 136, 2002.

[10] R. Rubiandini, Rancangan Teknik Pengeboran dan Komplesi. Bandung: ITB, 2012.

[11] M. D. D. Maharani and D. V. Sara, "Model Struktural Pengelolaan Tempat Penampungan dan Potong Ayam Secara Berkelanjutan Dalam Mendukung Ketahanan Pangan," in Peran Matematika, Sains, dan Teknologi dalam Mencapai Tujuan Pembangunan Berkelanjutan/SDGs, 2018, pp. 69-93. 